Research Article

\title{
Comparison of Co-trimoxazole and Cephalexin Efficacy in Preventing Urinary Tract Infection among Children
}

\author{
Jabar Parhiz $^{1}$ (D) , Sara Rahafard ${ }^{1 *}$ (D), Samaneh Sharifi ${ }^{1}$, Farshid Kompani ${ }^{1}$ \\ 1 Neonatal and Children's Health Research Center, Golestan University of Medical Sciences, \\ Gorgan, Iran \\ *Correspondence: Dr Sara Rahafard, Neonatal and Children's Health Research Center, Golestan \\ University of Medical Sciences, Gorgan, Iran \\ Tel: +989121949362 \\ Email: Dr.rahafard@gmail.com
}

\begin{abstract}
Received April 1, 2021
Accepted May 17, 2021

ABSTRACT

Background and objectives: Diagnosis and treatment of urinary tract infection (UTI) in children before kidney damage is necessary. The purpose of this study was to compare efficacy of co-trimoxazole and cephalexin in the prevention of recurrent UTI in children.

Methods: The study was performed on 100 children aged three months to 14 years who were referred to the Taleghani Pediatric Hospital in Gorgan (Iran) during 2016. The subjects had a history of UTI and required antibiotic prophylaxis to prevent UTI. They were divided into two groups of co-trimoxazole and cephalexin. Data were analyzed using SPSS (version 18) and at significance level of 0.05 .

Results: Recurrent UTI was observed in eight children (16.0\%) taking cephalexin and in six children $(12.0 \%)$ receiving co-trimoxazole $(\mathrm{p}=0.56)$. Urine culture examination revealed Escherichia coli as the causative agent of UTI in six cases $(75 \%)$ receiving cephalexin and in five cases $(83.3 \%)$ receiving co-trimoxazole $(\mathrm{p}=0.70)$. It should be noted that unilateral moderate hydronephrosis was the most frequent anomaly $(n=26)$ in the study groups.

Conclusion: According to the results of the present study, both cephalexin and co-trimoxazole have similar efficacy in the prevention of UTI among children.

Keywords: Urinary tract infection; Children; Recurrent infection; Co-trimoxazole; Cephalexin
\end{abstract} DOI: 10.29252/Jcbr.5.2.17 (c) (1) (3)

This work is licensed under a Creative Commons Attribution 4.0 License.

(C) The authors 


\section{INTRODUCTION}

Most children with urinary tract infection (UTI) have nonspecific or atypical symptoms and may present with diarrhea, vomiting, etc. In children with fever of unknown origin, a urine culture should be performed to rule out UTI. In a study, about $80 \%$ of infants with UTI who had a positive urine culture had a fever of unknown origin (1). Although factors, such as viruses, fungi and parasites are capable of causing UTIs, clinically important infections are usually caused by bacteria. The most common causes of UTI in children are Escherichia coli and Klebsiella pneumoniae from the Enterobacteriaceae family of bacteria. These bacteria can infect the urinary tract in ascending urethra, but bloodstream infections can also occur in rare cases. In addition, UTI may involve the bladder or the upper parts of the urinary tract, such as the urethra, the urinary collecting system and the kidney parenchyma (pyelonephritis). Increased occurrence of UTI is a complex process associated with host genetic and anatomical characteristics as well as invasion, virulence and bacterial locomotor properties of the pathogen (2).

In female students, the recurrence rate of UTI was estimated to be $40 \%$ within one year after the primary infection, while it was reported to be $30 \%$ among male students (3).There are two types of recurrences: relapse and reinfection. Relapse is defined as recurrent infection with the same strain, while reinfection means recurrent infection with a different strain (4). Recurrent UTI is often referred to as two or more UTIs in six months. Recurrent UTI risk factors include vesicoureteral reflux, urinary tract disorders, neurogenic bladder, urinary dysfunction, constipation, immunodeficiency, hypercalciuria and urinary stone. Antibiotic prophylaxis is recommended for cases at high risk of kidney damage or urosepsis, including a high degree of reflux, urinary tract obstruction, recurrent symptomatic UTI, bladder dysfunction and urinary dysfunction (ㅁ).
Children with vesicoureteral reflux (VUR) are at greater risk for recurrent UTI compared to those without VUR, and the reflux grade III and IV are associated with the highest risk. Another important factor in VUR is recurrent bladder dysfunction. Prevention of recurrent UTI in these patients involves antibiotic prophylaxis and treatment of bladder dysfunction (ㅁ) . Therefore, long-term antibiotic prophylaxis should be considered in high-risk children to prevent kidney damage. Different drugs such as co-trimoxazole (trimethoprimsulfamethoxazole), nitrofurantoin, nalidixic acid, ciprofloxacin and cephalexin have been recommended as prophylaxis to prevent UTI in children (7).Routine use of nitrofurantoin in bacterial eradication has not been effective in patients with chronic neurogenic bladder(요). Gastrointestinal intolerance is the most common side effect of nitrofurantoin (9). Nalidixic acid is one of the most important causes of pseudotumor cerebri in infants (10). Increasing resistance to antibiotics makes it difficult to treat the patients. More than $50 \%$ of E. coli strains are resistant to amoxicillin and ampicillin. Resistance to co-trimoxazole and cephalosporins is also increasing $(\underline{11}, \underline{12})$. The rate of microbial resistance in each region may vary over the years (13).In this study, we compare the efficacy of cotrimoxazole and cephalexin in preventing recurrence of UTI in children referred to the Taleghani Hospital in Gorgan, north of Iran.

\section{MATERIAL AND METHODS}

This cohort study was conducted on children aged three months to 14 years old who were referred to the Taleghani Pediatric Hospital with a history of UTI. The study was approved by the ethics committee of Golestan University of Medical Sciences (approval code: IR.GOUMS.REC.1398.175). Based on the study by Ghane Sharbaf et al. (14) and given the recurrence rate of $21.1 \%$ in the cotrimoxazole group and $48 \%$ in the nalidixic 
acid group, the sample size of 50 was considered for each group. Data were collected through interviews, examinations and checklists. Complete urine test and culture were performed to confirm UTI. For all children, kidney and urinary tract ultrasonography were performed by an experienced sonographer, and also the standard voiding cystourethrogram (VCUG) or radionuclide cystogram (RNC) were carried out based on indications, including the presence of pyelonephritis or any abnormality on ultrasonography in the presence of a UTI.

After treatment of acute infection, the subjects were divided into two groups and underwent prophylaxis with either trimethoprim-sulfamethoxazole or cephalexin based on results of the antibiotic susceptibility test. These evaluations were performed more frequently whenever there was suspicion of UTI based on the recurrence of symptoms. Recurrence was considered as a new UTI with the same or a different strain of pathogens. During the study, all demographic data including age, gender as well as information on antibiotic prophylaxis, underlying diseases and urinary anomalies were recorded. The subjects included children who were at risk for recurrent UTI and on prophylaxis with cotrimoxazole or cephalexin including those with grade 3 or higher urinary tract reflux, bladder dysfunction, urinary tract obstruction, recurrent UTIs (at least two
UTIs within six months) as well as those who developed UTI while taking the prophylactic drugs. Exclusion criteria were failure to parental follow-up, drug intolerance and stopping the medication by the patient.

Data were analyzed using SPSS (version 18). The Shapiro-Wilk test was used to check normal distribution of data. The chisquare test, t-test and Mann-Whitney test were used to analyze quantitative and qualitative variables. A p-value of less than 0.05 was considered significant.

\section{RESULTS}

In this study, 100 children (48 male) aged three months to 14 years with a history of UTI who needed antibiotic prophylaxis to prevent UTI were enrolled. The subjects were equally divided into a cephalexin and a co-trimoxazole group. To further assess the effects of the drugs, children were qualitatively divided into two groups of less than 4 and older than 5 years old.

The mean age of children was $44.51 \pm 43.75$ months, ranging from three months to 13 years (156 months). The subjects were matched in terms of age and gender (Table 1).

Overall, the recurrence rate of UTI was $14 \%$ among the subjects. Moreover, UTI recurrence rate was found to be $16 \%$ in children receiving cephalexin and $12 \%$ in children receiving co-trimoxazole. The difference between the two groups was not statistically significant $\quad(\mathrm{p}=0.56)$. 
Table 1. Distribution of subjects in the study groups according to age and gender

\begin{tabular}{|c|c|c|c|}
\hline \multirow{2}{*}{ Variable } & Cephalexin group & Co-trimoxazole group & \multirow{2}{*}{ P-value } \\
\cline { 2 - 3 } & Frequency (\%) & Frequency (\%) & \\
Gender & $25 / 48(52.1 \%)$ & $23 / 48(47.9 \%)$ & \multirow{2}{*}{0.68} \\
Male & $25 / 52(48.1 \%)$ & $27 / 52(51.9 \%)$ & \\
Female & & & \\
\hline & & & \\
Age (years) & $37 / 69(53.7 \%)$ & $18 / 31(58.1 \%)$ & \\
less than 4 & $13 / 31(41.9 \%)$ & & \\
more than 5 & & & \\
& & & \\
\hline
\end{tabular}

When comparing the time of UTI recurrence between the two groups, it was found that the mean recurrence time was $1.12 \pm 1.88$ months in the children receiving cephalexin and $1.21 \pm 2.33$ months in the children receiving co-trimoxazole $(\mathrm{p}=0.49)$. In the urine culture analysis, out of 14 UTI recurrences, 11 cases $(78.6 \%)$ were caused by E. coli and three cases $(21.4 \%)$ were caused by Pseudomonas spp. In the cotrimoxazole group, one case $(16.7 \%)$ of Pseudomonas spp. and five cases $(83.3 \%)$ of E. coli infections were observed in the cultured samples. However, there was no significant difference between the two groups in terms of the causative bacteria $(p=0.70)$. Moreover, there was no significant difference between the two groups in ultrasonography results $(\mathrm{p}=0.16)$ (Table 2). It should be noted that unilateral moderate hydronephrosis was the most frequent finding ( $\mathrm{n}=26$ cases).

In the cephalexin group, 17 cases $(34.0 \%)$ had normal RNC or VCUG and 13 cases $(26.0 \%)$ had grade IV vesicoureteral reflux. In the co-trimoxazole group, 22 cases (44.0\%) had normal RNC or VCUG results and 10 cases $(20.0 \%)$ had grade IV. However, the difference between the two groups was not statistically significant $(\mathrm{p}=0.47)$ (Figure 1).

The findings indicated that 14 children (23\%) with abnormal RNC or VCUG had a UTI recurrence, which was statistically significant $(\mathrm{p}=0.001)$ (Table 3). Also, the recurrence rate of UTI based on reflux grade showed that nine children $(39.1 \%)$ with grade IV had a recurrence of infection, which was statistically significant (p $<0.001$ ) (Table 3). 


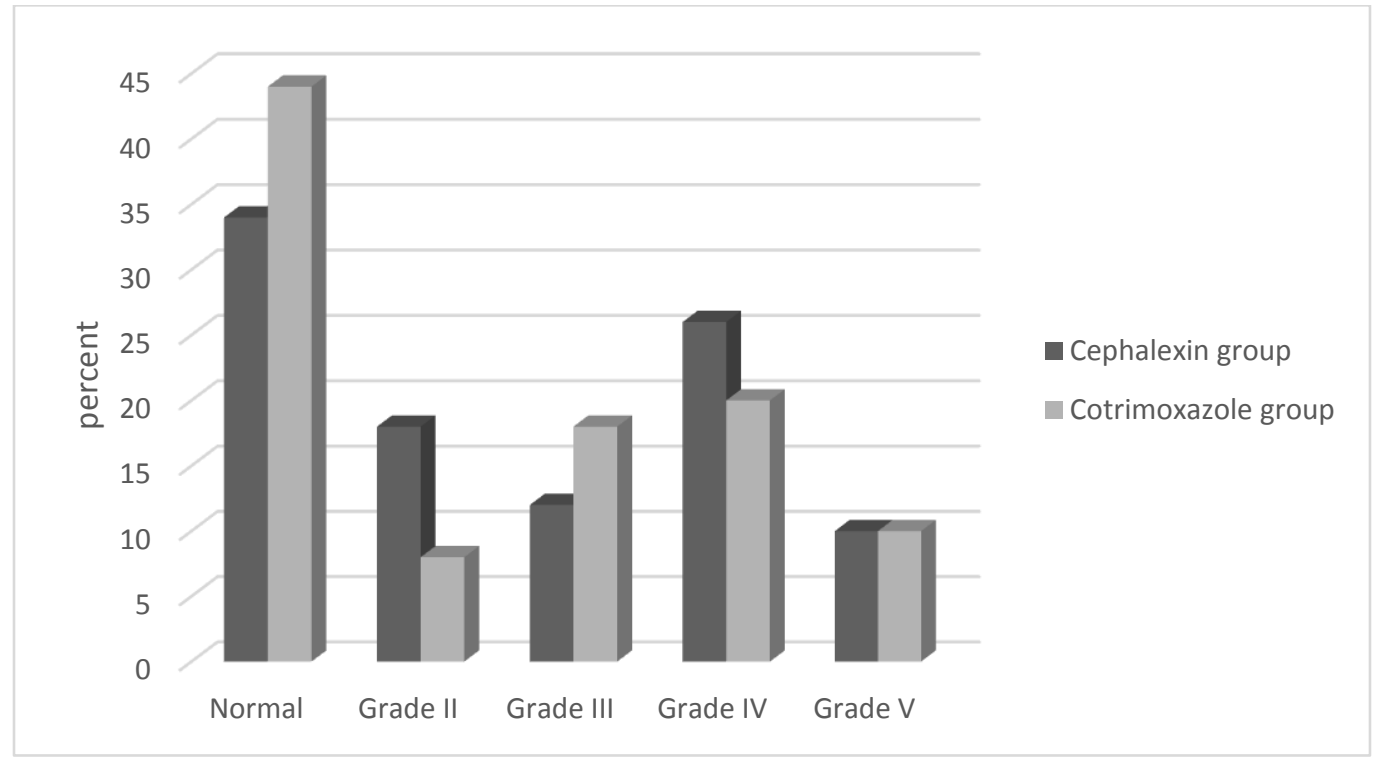

Figure 1. Comparison of RNC or VCUG results between the two study groups

Table 2. Evaluation of the results of urinary ultrasound in children receiving cephalexin and cotrimoxazole

\begin{tabular}{|c|c|c|c|}
\hline Ultrasound findings & $\begin{array}{c}\text { Cephalexin } \\
\text { group }\end{array}$ & $\begin{array}{c}\text { Cotrimoxazole } \\
\text { group }\end{array}$ & P-value* \\
\hline $\begin{array}{c}\text { Unilateral Moderate } \\
\text { hydronephrosis }\end{array}$ & Frequency (\%) & Frequency (\%) & $16 / 26(61.5 \%)$ \\
\hline Normal & $14 / 22(63.6 \%)$ & $8 / 22(36.4 \%)$ \\
\hline $\begin{array}{c}\text { Unilateral mild } \\
\text { hydronephrosis }\end{array}$ & $6 / 19(31.6 \%)$ & $13 / 19(68.4 \%)$ \\
\hline $\begin{array}{c}\text { Bilateral mild } \\
\text { hydronephrosis }\end{array}$ & $7 / 13(53.8 \%)$ & $6 / 13(46.2 \%)$ \\
\hline $\begin{array}{c}\text { Unilateral severe } \\
\text { hydronephrosis }\end{array}$ & $\begin{array}{c}(5 / 6 \%) \\
\text { Bilateral moderate } \\
\text { hydronephrosis }\end{array}$ & $6 / 6(100 \%)$ & $3 / 6(50 \%)$ \\
\hline Trabecular bladder & $2 / 3(66.7 \%)$ & $1 / 3(33.3 \%)$ \\
\hline $\begin{array}{c}\text { Bilateral polycystic kidney } \\
\text { Bilateral severe } \\
\text { hydronephrosis }\end{array}$ & $1 / 2(50 \%)$ & $1 / 2(50 \%)$ \\
\hline Double ureter & $1 / 2(50 \%)$ & $1 / 2(50 \%)$ \\
\hline
\end{tabular}

* Based on the results of the chi-square test 
Table 3. Differences of ultrasound findings in patients with and without UTI recurrence

\begin{tabular}{|l|l|l|l|}
\hline \multirow{2}{*}{ Variables } & Non-recurrence & Recurrence & \multirow{2}{*}{ P-value* } \\
\cline { 2 - 3 } & Frequency (\%) & Frequency (\%) & \\
\hline Ultrasound findings & & & \\
Normal & $21 / 22(95.5 \%)$ & $1 / 22(4.5 \%)$ & 0.14 \\
Abnormal & $65 / 78(83.3 \%)$ & $13 / 78(16.7 \%)$ & \\
\hline Urinary dysfunction & & - & \\
Normal & $39 / 39(100 \%)$ & $14 / 61(23 \%)$ & \\
Abnormal & $47 / 61(77 \%)$ & & \\
\hline Grade of Reflux & & - & \\
Normal & $39 / 39(100 \%)$ & $9 / 23(39.1 \%)$ & \\
Grade IV & $14 / 23(60.95)$ & $1 / 15(6.7 \%)$ & \\
Grade III & $14 / 15(93.3 \%)$ & $1 / 13(7.7 \%)$ & \\
Grade II & $12 / 13(92.3 \%)$ & $3 / 10(30 \%)$ & \\
Grade V & $7 / 10(70 \%)$ & & \\
\hline
\end{tabular}

* Based on the results of the chi-square test

\section{DISCUSSION}

As mentioned earlier, UTI is one of the most common bacterial infections in children. These infections affect the kidney, ureter or bladder (15). Given the limitations of studies on the use of appropriate prophylactic medication in children with recurrent UTI, and also the regional differences in the antibiotic sensitivity patterns, this study was performed to compare the efficacy of co-trimoxazole and cephalexin in the prevention of recurrent UTI in children aged three months to 14 years. The main finding of the present study was that the incidence of recurrence was not considerably different between the cotrimoxazole and cephalexin groups. In other words, the two drugs acted similarly in preventing UTI recurrence in children. In a similar study by Amirhassani et al., the efficacy of nalidixic acid and co-trimoxazole was not significantly different (16). However, a study by Ghanesharbaf et al. showed that prophylaxis with cotrimoxazole is preferable over nalixic acid in children with UTI (14). The risk of UTI recurrence in children is $30 \%$ after the first infection and $70 \%$ after the third infection; therefore, it is necessary to prevent longterm antibiotic prophylaxis in high-risk children (17). Amini et al. found that the rate of resistance to co-trimoxazole and cephalexin was approximately equal (18). One of the strengths of the present study was to compare the time of UTI recurrence in both groups. The duration of recurrence was two months in children taking cotrimoxazole and one month in children under cephalexin therapy. Furthermore, the prevalence of recurrent UTI was $14 \%$ in the studied children. A study by Dodge et al. reported a recurrence rate of approximately $21 \%$ for UTI (19). Sorkhi et al. reported a recurrence rate of $22.6 \%$ for UTI among children (20). In another study, Gillenwater et al. reported that about $25 \%$ of people with UTI relapsed (21). The rate of recurrence in these studies is higher than the rate observed in our study. This may be due to the difference in sample size, voiding dysfunction and the reflux grades, which may affect the results.

In the present study, E. coli followed by Pseudomonas spp. were identified as the most common causes of UTI. However, there was no significant difference between the two groups in terms of causative agent of UTI recurrence. It is known that UTIs are mainly caused by gram-negative bacilli and E. coli (22). Previous studies also reported E. coli as the most common isolate from UTI $(\underline{23}, \underline{24})$. 
According to the results of ultrasonography of pediatric urethra, hydronephrosis was the most frequent anomaly in the study groups. In a study conducted by Hemmatyar et al. with a subsequent follow-up, there was no case of urinary reflux on VCUG (25).which is in line with our findings.

UTI is an important cause of progressive scarring, degeneration of kidney structures, renal failure, urinary stones and hypertension in children (26).Therefore, early diagnosis and treatment with proper antibiotics are essential to prevent these complications. In our study, the number of normal cases of RNC or VCUG in children under co-trimoxazole therapy was 1.2 times more than in those on cephalexin, but there was no significant difference between the two groups. Similar to our findings, Neilson stated that 10 to $35 \%$ of vesicular reflux cases had underlying malformations (27).Litaka et al. also found that $21 \%$ of children with permanent bacteriuria had anomalies (묘).

\section{CONCLUSION}

According to the results of the present study, both cephalexin and co-cotrimoxazole have similar efficacy in preventing the recurrence of UTI in children. Either of these two antibiotics could be used on the basis of patient tolerance and the antibiotic susceptibility pattern.

\section{ACKNOWLEDGEMENTS}

None.

\section{DECLARATIONS \\ Funding}

The study has received financial support from the Golestan University of Medical Sciences, Gorgan, Iran.

\section{Ethics approvals and consent to participate}

Consent was obtained from the subjects' parents after ensuring the confidentially of personal information. The study was approved by the ethics committee of Golestan University of Medical Sciences (approval code: IR.GOUMS.REC.1398.175).

\section{Conflict of interest}

The authors declare that there is no conflict of interest regarding publication of this article.

\section{REFERENCES}

1. Newman TB. The new American Academy of Pediatrics urinary tract infection guideline. Pediatrics. 2011;128(3):572-5. [View at Publisher] [DOI] [PubMed] [Google Scholar]

2. Taneja N, Chatterjee SS, Singh M, Singh S, Sharma M. Pediatric urinary tract infections in a tertiary care center from north India. Indian journal of medical research. 2010;131(1):101-6. [PubMed] [Google Scholar]

3. Swerkersson S. Urinary tract infection in small children: aspects of bacteriology, vesicoureteral reflux and renal damage. 2016. [View at Publisher] [Google Scholar]

4. Yousefi P, Cyrus A, Moghaddasi Z, Dorreh F, Aravand A. The frequency of recurrence of urinary tract infection (UTI) in 1-month to 12-year-old children without congenital abnormalities referred to Arak Amir Kabir Hospital. J Adv Med Biomed Res. 2011;19(76):66-76. [View at Publisher] [Google Scholar]

5. Nickavar A, Sotoudeh K. Treatment and prophylaxis in pediatric urinary tract infection. International journal of preventive medicine. 2011;2(1):4. [View at Publisher] [PubMed] [Google Scholar]

6. Keren R, Shaikh N, Pohl H, GravensMueller L, Ivanova A, Zaoutis L, et al. Risk factors for recurrent urinary tract infection and renal scarring. Pediatrics. 2015;136(1):e13-e21. [View at Publisher] 
[DOI] [PubMed] [Google Scholar]

7. Kliegman RM, Behrman RE, Jenson HB, Stanton BM. Nelson textbook of pediatrics e-book: Elsevier Health Sciences; 2007. [View at Publisher] [Google Scholar]

8. Chaudhry R, Balsara ZR, MaddenFuentes RJ, Wiener JS, Routh JC, Seed P, et al. Risk factors associated with recurrent urinary tract infection in neurogenic bladders managed by clean intermittent catheterization. Urology. 2017;102:213-8.

[View at Publisher] [DOI] [PubMed] [Google Scholar]

9. Karpman E, Kurzrock EA. Adverse reactions of nitrofurantoin, trimethoprim and sulfamethoxazole in children. The Journal of urology. 2004;172(2):448-53. [View at Publisher] [DOI] [PubMed] [Google $\underline{\text { Scholar] }}$

10. Simalti A. Pseudotumour cerebri: A side-effect of nalidixic acid. Acta Medica International. 2014;1(1):325-37. [View at Publisher] [DOI] [Google Scholar]

11. Falagas ME, Polemis M, Alexiou VG, Marini-Mastrogiannaki A, Kremastinou J, Vatopoulos AC. Antimicrobial resistance of Esherichia coli urinary isolates from primary care patients in Greece. Medical Science Monitor. 2008;14(2):CR75-CR9. [View at Publisher] [PubMed] [Google Scholar]

12. Cheng C-H, Tsai M-H, Huang Y-C, Su L-H, Tsau Y-K, Lin C-J, et al. Antibiotic resistance patterns of community-acquired urinary tract infections in children with vesicoureteral reflux receiving prophylactic antibiotic therapy. Pediatrics. 2008;122(6):1212-7. [View at Publisher] [DOI] [PubMed] [Google Scholar]

13. Valavi E, Nikfar R, Ahmadzadeh A, Kompani F, Najafi R, Hoseini R. The last three years antibiotic susceptibility patterns of uropathogens in southwest of Iran. 2013.
[View at Publisher] [DOI] [Google Scholar]

14. Ghane Sharbaf F, Esmaeili M, Esmaeili M. Comparison of Nalidixic acid and Trimethoprim â sulfamethoxazole in prophylaxis of recurrent urinary tract infection in children. medical journal of mashhad university of medical sciences. 2015;58(4):175-84. [View at Publisher] [Google Scholar]

15. Bryce A, Hay AD, Lane IF, Thornton HV, Wootton M, Costelloe C. Global prevalence of antibiotic resistance in paediatric urinary tract infections caused by Escherichia coli and association with routine use of antibiotics in primary care: systematic review and meta-analysis. bmj. 2016;352. [View at Publisher] [DOI] [PubMed] [Google Scholar]

16. Amirhassani S, Mosavi Bahar SHA. Comparative Study of Effectiveness of Long Term Low Dose of Naldixic Acid and Cotrimoxazolee in Patients with Recurrent Urinary Tract Infections. Avicenna Journal of Clinical Medicine. 2012;19(1):11-5. [View at Publisher] [Google Scholar]

17. Mori R, Fitzgerald A, Williams C, Tullus K, Verrier - Jones K, Lakhanpaul M. Antibiotic prophylaxis for children at risk of developing urinary tract infection: a systematic review. Acta Paediatrica. 2009;98(11):1781-6. [View at Publisher] [DOI] [PubMed] [Google Scholar]

18. Karimpour HA, Mohamadi S. The study of frequency and antibiotic resistance pattern of urinary tract infection pathogens in children of Kermanshah in 2015. Razi Journal of Medical Sciences. 2017;24(155):20-7. [View at Publisher] [Google Scholar]

19. Dodge WF, West EF, Travis LB. Bacteriuria in school children: Observations on outcome following detection in 110 girls. American Journal of Diseases of Children. 
1974;127(3):364-70. [View at Publisher] [DOI] [PubMed] [Google Scholar]

20. Sorkhi H, Zamani N, Bijani A. Evaluation of discontinuation of antibacterial prophylaxis in children with vesicoureteral reflux. Journal of Shahrekord University of Medical Sciences. 2012;14(3):72-80. [View at Publisher] [Google Scholar]

21. Gillenwater JY, Harrison RB, Kunin CM. Natural history of bacteriuria in schoolgirls: A long-term case-control study. New England Journal of Medicine. 1979;301(8):396-9. [View at Publisher] [DOI] [PubMed] [Google Scholar]

22. Paschke AA, Zaoutis T, Conway PH, Xie D, Keren R. Previous antimicrobial exposure is associated with drug-resistant urinary tract infections in children. Pediatrics. 2010;125(4):664-72. [View at Publisher] [DOI] [PubMed] [Google Scholar]

23. Zainal D, Baba A. The value of positive nitrites in screening asymptomatic bacteriuria amongst Malaysian school children. The Southeast Asian journal of tropical medicine and public health. 1996;27(1):184-8. [View at Publisher] [PubMed] [Google Scholar]
24. Vincent C, Boerlin P, Daignault D, Dozois CM, Dutil L, Galanakis C, et al. Food reservoir for Escherichia coli causing urinary tract infections. Emerging infectious diseases. 2010;16(1):88. [View at Publisher] [DOI] [PubMed] [Google Scholar]

25. Sabzehei MK, Basiri B, Shokouhi M, Eghbalian F. Urinary tract infection profile among a hospitalized newborn: a single center study in Iran, 2006-2015. Medical Journal of Indonesia. 2018;27(2):94â 10094â. [View at Publisher] [DOI] [Google Scholar]

26. Bremberg SG, Edström S. Outcome assessment of routine medical practice in handling child urinary tract infections: estimation of renal scar incidence. Ambulatory child health. 2001;7(3 - 4):14955. [View at Publisher] [Google Scholar]

27. Neilson EG. Pathogenesis and therapy of interstitial nephritis. Kidney international. 1989;35(5):1257-70. [View at Publisher] [DOI] [PubMed] [Google Scholar]

28. Litaka K, Sakai T, Oyama K, Izawa T, Igarashi S. Screening for bacteriuria in Japanese school children. Pediatrics International. 1990;32(6):690-5.

[View at Publisher] [DOI] [Google Scholar]

How to Cite: Parhiz J, Rahafard S, Sharifi S, Kompani F. Comparison of Co-trimoxazole and Cephalexin Efficacy in Preventing Urinary Tract Infection among Children. Journal of Clinical and Basic Research. 2021; 5 (2) :17-25 